\title{
Evaluation of Early Post-Operative Complications of Hysterectomized Patients
}

Dr. Most Fatima Dolon ${ }^{1 *}$, Dr. Khadiza Rubab ${ }^{2}$, Dr. Nabid Shahriar ${ }^{3}$, Dr. Most Dilara Akter ${ }^{4}$, Dr. Mahmuda Naher ${ }^{5}$, Dr. Jubaida Sultana ${ }^{6}$, Dr. Ehsen Ara ${ }^{7}$

\footnotetext{
${ }^{1}$ Senior Consultant, Department of Obstetrics and Gynaecology, Shaheed Tazuddin Ahmad Medical College \& Hospital, Gazipur, Bangladesh

${ }^{2}$ Diploma in Course Obstetrics \& Gynaecology of Bangabandhu Sheikh Mujib Medical University, Dhaka, Bangladesh

${ }^{3}$ Diploma in Course Anaesthesiology of Bangabandhu Sheikh Mujib Medical University, Dhaka, Bangladesh

${ }^{4}$ Assistant Professor, Department of Community Medicine, Shaheed M. Monsur Ali Medical College, Sirajganj, Bangladesh

${ }^{5}$ Junior Consultant, Department of Obstetrics and Gynaecology, Shaheed Tazuddin Ahmad Medical College, Gazipur, Bangladesh

${ }^{6}$ Assistant Professor, Shaheed Tazuddin Ahmad Medical College, Gazipur, Bangladesh

${ }^{7}$ Senior Consultant, Gynae Sadar Hospital, Satkhira, Bangladesh
}

\section{*Corresponding author: Dr. Most Fatima Dolon}

Background: Hysterectomy is the surgical removal of the uterus. In a total hysterectomy, the uterus and cervix are removed. In some cases, the fallopian tubes and ovaries are removed along with the uterus. In subtotal hysterectomy, only the uterus is removed. Infectious complications after hysterectomy are most common, ranging from $10.5 \%$ for abdominal hysterectomy to $13.0 \%$ for vaginal hysterectomy and $9.0 \%$ for laparoscopic hysterectomy [1]. Objective: The purpose of the study was to evaluation of the early post-operative complication of Hysterectomized patients. Methods: The Study was conducted in the department of obstetrics and gynaecology of Dhaka Medical College Hospital, Dhaka, Bangladesh to find out the common indications of hysterectomy. 100 cases were randomly selected for the study whose common indication of hysterectomy. Clinical examination and evaluation were done from October 2004 to February 2005. Other necessary investigations were done if clinically indicated and to prepare the patient for anesthesia. Statistical analysis of the results was obtained by using window-based computer software devised with Statistical Packages for Social Sciences (SPSS-22). Results: Majority of cases who underwent hysterectomy were 3140 years $(52 \%)$ of age. Out of 100 cases most of patients $(70 \%)$ underwent abdominal hysterectomy and only 30 $(30 \%)$ cases underwent vaginal hysterectomy. Out of 33 cases, clinically diagnosed as leiomyoma of the uterus histopathology revealed leiomyoma in 24 cases. In uncomplicated abdominal and vaginal hysterectomy, the duration of surgery was almost same, vaginal hysterectomies needs slightly longer time. Average hospital stay after operation was same. Conclusion: Uterine weight was not affected the complication rate, estimated blood loss and length of hospital stay in total hysterectomy operation.

Keywords: Hysterectomy; Abdominal; Gynecological; Premalignant.

Copyright $\left({ }_{0} 2021\right.$ The Author(s): This is an open-access article distributed under the terms of the Creative Commons Attribution 4.0 International License (CC BY-NC 4.0) which permits unrestricted use, distribution, and reproduction in any medium for non-commercial use provided the original author and source are credited.

\section{INTRODUCTION}

Complications of hysterectomy vary based on route of surgery and surgical technique. Abdominal hysterectomy remains the most common route of surgery despite a longer hospital stay, more postoperative pain, a higher rate of infection, and slower return to normal activities [1]. The story of hysterectomy dates back to the middle of 19th century when it was first performed. The progress until now in the techniques of hysterectomy proves the remarkable improvement in the surgical art of gynecology. Abdominal hysterectomy was performed many years after ovariotomy was being done. Abdomen was first deliberately opened to remove an ovarian cyst by Ephraim Macdowell in Kentucky in 1809 [2]. In 1843 Charles clay of Manchester performed abdominal hysterectomy. But the patient died in immediate postoperative period. In 1853 Dr. Walter Burnham from Lowell Massachusetts achieved the first successful abdominal hysterectomy for removal of anterior leiomyoma of uterus. The survival of the patient encouraged him to attempt further hysterectomy. Of his next 15 cases only 3 survived.

Lawson trait attempted to solve the problem of leiomyomata by castrations by means of bilateral 
oophorectomy. In 1880 C.D. Palmer reviewed a total of 119 hysterectomies collected from the literature, mortality was $75 \%$. The main problem of hysterectomy at that time was management of the cervical stump liable to infection, hemorrhage and death. Vaginal hysterectomy was performed in 1813 by Laugenback in Germany and in 1819 by John Colins Waraen in Boston. Both operations were unsuccessful. Fenger described the modem operation of vaginal hysterectomy in 1881 .

Radical vaginal hysterectomy was first performed by Schauta in 1908. Wertheim of Vienna who established radical abdominal type of hysterectomy with selective pelvic lymphadenectomy in 1898 by performing an extensive series for carcinoma cervix [3]. Hysterectomy became safer with introduction of anesthesia, antibiotics, antiseptics, blood transfusion and intravenous therapy and introduction of modem methods of sterilization. During the 1930s Richardson introduced the total abdominal hysterectomy. The transverse incision introduced by Johanns Pfannensteil in the 1920. Laparoscopic hysterectomy was first performed by Harry Reich in Kingston Pennsylvania in 1988 and it is first published in 1989 by Riech et al. and many modifications and developments to this technique have been describe [4]. Dicker et al. in 1982 showed that complication rate in laparoscopic vaginal hysterectomy is much less than traditional abdominal hysterectomy, it is $15.6 \%$ and $42.8 \%$ respectively [5]. The refinement and increasing safety of laparoscopic hysterectomy suggest that it will be used increasingly in the future.

\section{OBJECTIVE}

The purpose of the study was to evaluation of the early post-operative complication of Hysterectomized patients.

\section{METHODS}

The Study was conducted in the department of obstetrics and gynaecology of Dhaka Medical College Hospital, Dhaka, Bangladesh to find out the common indications of hysterectomy. 100 cases were randomly selected for the study whose common indication of hysterectomy. Clinical examination and evaluation were done from October 2004 to February 2005. Other necessary investigations were done if clinically indicated and to prepare the patient for anesthesia. Then the cases were again evaluated according to preoperative findings. Finally, the specimen was sent for histopathological examination and correlated with clinical and preoperative findings. Statistical analysis of the results was obtained by using window-based computer software devised with Statistical Packages for Social Sciences (SPSS-22).

\section{RESULTS}

Majority of cases who underwent hysterectomy were $31-40$ years $(52 \%)$ of age. The total study population was 100 Patients aged 21 years to $\geq 80$ years, $6.0 \%$ were 21 years to 30 years, $52.0 \%$ were 31 years to 40 years, $28.0 \%$ were 41 years to 50 years, $6.0 \%$ were 51 years to 60 years, $5.0 \%$ were 61 years to 70 years and $3.0 \%$ ware $\geq 80$ years. Out of 100 cases most of patients (70\%) underwent abdominal hysterectomy and only $30(30 \%)$ cases underwent vaginal hysterectomy. Every patient received prophylactic antibiotics pre-operatively with ciprofloxacin and metronidazole or amoxicillin, gentamycin and metronidazole. Among the 100 cases studied, 9 patients suffered from low grade fever which cured by broad spectrum antibiotic and also metronidazole therapy. One patient develops PDPH which was treated with rapid volume replacement with hartmanns saline infusion and analgesics.

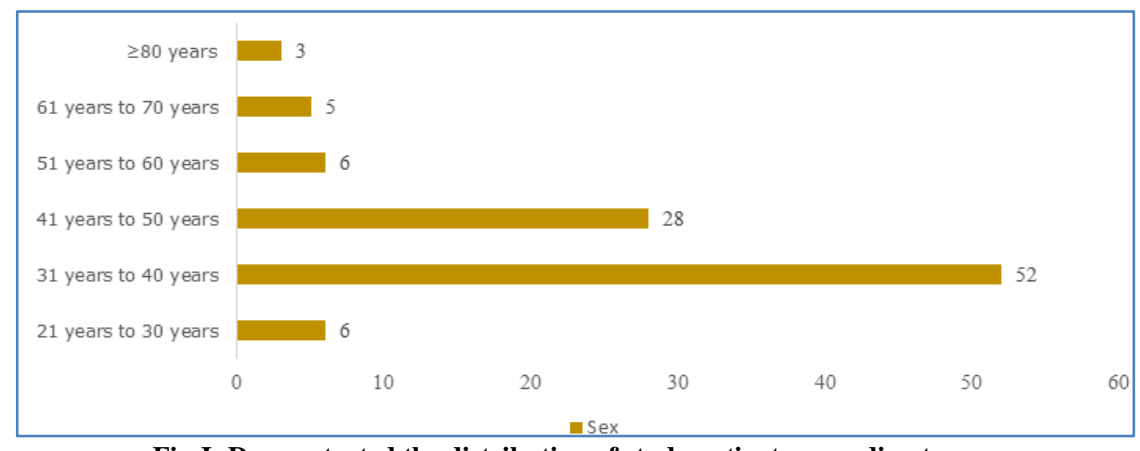

Fig-I: Demonstrated the distribution of study patients according to age.

Table-I: Demonstrated the distribution of study patients according to Types of Hysterectomy.

\begin{tabular}{|c|c|c|}
\hline Types of Hysterectomy & $\mathrm{n}=\mathbf{1 0 0}$ & $\%$ \\
\hline \multicolumn{3}{|l|}{ Abdominal Hysterectomy } \\
\hline Total Abdominal Hysterectomy & 68 & 68.0 \\
\hline Sub-total Hysterectomy & 2 & 2.0 \\
\hline \multicolumn{3}{|l|}{ Vaginal Hysterectomy } \\
\hline For utero-vaginal Prolapse & 26 & 26.0 \\
\hline Non-decent vaginal Hysterectomy & 2 & 2.0 \\
\hline LAVH & 2 & 2.0 \\
\hline
\end{tabular}




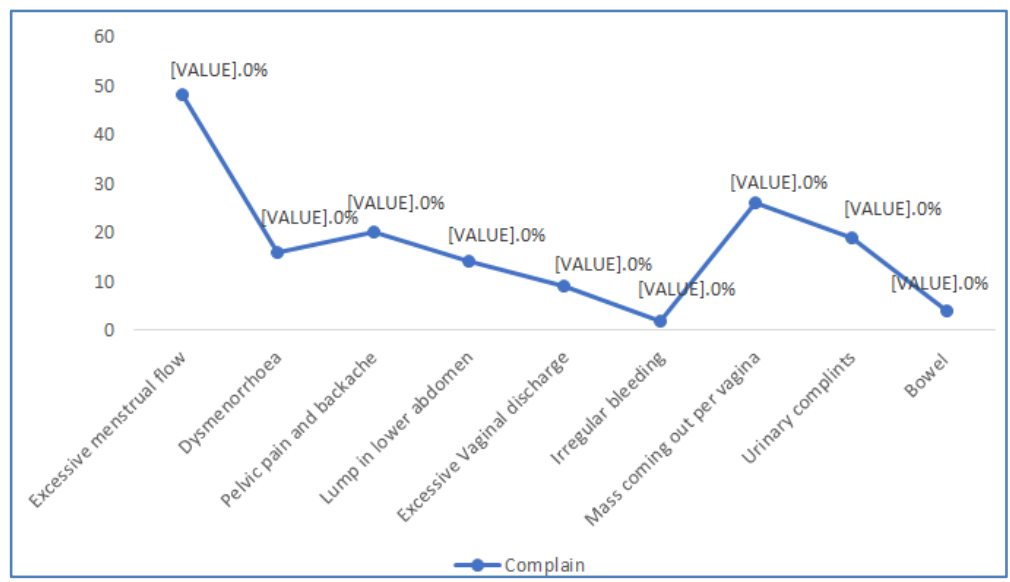

Fig-II: Demonstrated the distribution of study patients according to complain.

Table II: Demonstrated the distribution of study patients according to complication.

\begin{tabular}{|l|l|l|}
\hline Complications & $\mathbf{n = 1 0 0}$ & $\mathbf{\%}$ \\
\hline Fever & 9 & 9.0 \\
\hline Urinary tract infection & 6 & 6.0 \\
\hline Respiratory tract infection & 4 & 4.0 \\
\hline Abdominal wound infection & - & - \\
\hline Post dural puncture headache (PDPH) & 1 & 1.0 \\
\hline Seconday hemorrhage & - & - \\
\hline Pelvic infection & - & - \\
\hline Vault granuloma & - & - \\
\hline
\end{tabular}

\section{DISCUSSION}

This study has been performed to find the common indications, complications and morbidity of hysterectomy and to correlate the clinical presentation with the peroperative and hystopathological findings. In the present study, it was observed that maximum number $(80 \%)$ of hysterectomies was done in women between the age of 31 - 50 years. Similar age incidence reported by a1most similar findings were observed in other studies [6-10]. Regarding symptomatology, it was observed that abnormal menstrual flow was the single most common complaints other studies reported hysterectomy due to menstrual disorders [11-15].

Leiomyoma uterus was the most common indication $(33 \%)$ of hysterectomy somewhat similar results were reported other studies [6-10]. Hysterectomy was done for $9 \%$ cases of PID. It showed wide variation in different studies. Rechard C. Dicker 32 showed the incidence of $7.2 \%$ while steven $\mathrm{C}$. white 38 showed incidence of $1.6 \%$ Nancy C 36 showed 5\% and some study showed the incidence $2 \%$. Hysterectomies were done for DUB in $6 \%$ cases. It also showed a wide variation in different studies. In the present series out of $6 \%$ of DUB diagnosed preoperatively, histopathology revealed associated pathology in 5 cases. Only in one case uterus and cervix showed normal architexure on histopathology [16-20].

Utero-vaginal prolapse was the indication of vaginal hysterectomy in $26 \%$ cases. In other studies, also observed almost similar findings. According to Shergill et al. 27 Pokras and Hufnaged 37 and was the indication for hysterectomy in $24 \% 20.8 \%$ and $27 \%$ respectively. In $25 \%$ cases of total abdominal hysterectomy bilateral salpingo oophorectomy has been carried out. In $58 \%$ cases both ovaries were preserved. And in $17 \%$ cases of total abdominal hysterectomy one ovary was preserved in women below 45 years having clinically healthy ovaries. In vaginal hysterectomy, ovaries bad been retained after they had been detected normal on sonography but in one case patient had ovarian cyst which could not be removed vaginally and after vaginal hysterectomy laparatomy was done to remove that ovarian cyst. Out of 33 cases of clinically diagnosed leiomyoma was confmned on histopathology in 24 cases. Adenomyosis was found in 7 cases, all of them presented with menorrhagia and associated dysmenorrhoea in every cases uterus was $<12$ wk size.

Out of 8 cases of ovarian tumour 6cases were clinically diagnosed as benign ovarian tumour and 5 were confirmed as benign ovarian tumour on histopathology. In one case histopathology revealed granulosa cell tumour. 2 cases of clinically diagnosed malignant ovarian tumour were confirmed as malignant on histopathology. So, in most cases pre-operative clinical diagnosis was confirned on histopathological examinati $r$ correlation observed in the study Hysterectomy for endometriosis showed a wide variation in incidence between the different series? Some studys both have shown incidence of $7 \%$ whereas Steven. C. white 38 has shown $1.3 \%$. In the present series only 3 hysterectomies were done for external Endometriosis. The reason for these cases was that preoperatively endometriosis is often not very easy to diagnose clinically. 
Most Fatima Dolon et al., SAS J Surg, Mar, 2021; 7(3): 130-133

In the present series 4 hysterectomies had been done for chronic cervicitis. In two cases there were associated PID. In all cases histopathology confirm the diagnosis. But chronic cervicitis was an associated fmdings in 11 cases of leiomyoma of the uterus, 3 cases of DUB, 5 cases of PID 1 cases of endometriosis. In vaginal hysterectomy due to uterovaginal prolapse in all cases cervix showed feature of chronic cervicitis on histopathological examination. Regarding short term outcome vaginal hysterectomy was found to be advantageous in respect of cost of anesthesia and ambulation. Duration of operation was shortening in abdominal hysterectomy and duration of hospital stay was same in the both groups. Various other studies have shown similar outcome.

Regarding complications febrile morbidity was the commonest (9\%) complication after hysterectomy followed by urinary tract infection (8\%) Respiratory treat infection (4\%) Similar complication rate was observed by some similar studies Abdominal wound infection was found $6 \%$ in Razia S. series $5 \%$ in Richard C. series $4 \%$ in Dewan F.Series. But in the present series there was no such complication.

\section{CONCLUSION}

We have presented a review of the most common complications associated with hysterectomy and recommendations for prevention and management of these complications. As surgeons and health providers, our goal is to provide optimal care while exposing our patients to minimal risk. We can accomplish this by not only recognizing the potential surgical complications of hysterectomy but also using good surgical technique to avoid these complications and performing timely diagnosis and treatment of any complications. Although we cannot avoid all surgical complications, we can strive to minimize the risks for women undergoing hysterectomy.

\section{REFERENCES}

1. Clarke-Pearson DL, Geller EJ. Complications of hysterectomy. Obstetrics \& Gynecology. 2013 Mar 1;121(3):654-73.

2. Sutton C. Hysterectomy: a historical perspective. Baillieres-c1in- obstet Gynaecol. 1997; 11(1): 122.

3. Jeffcoate's N .Hysterectomy and its Aftermath in Jeffcoat's Principles of Gynaecology.Intemational editiome") BhatIa N.(editor), London, Arnold. 2001;785- 790 .

4. Reich H. De Caprio J \& McGlynn F. Laparoscopic hysterectomy. J Gynecol Surg. 1989; 5: 213-217.

5. Dicker. Complications of abdominal and vaginal hysterectomy among women of reproductive age in the United States. Am J Obstet Gynecol. 1982; 144: 841-848.
6. Razia S. Clinicopathological study of hysterectomy in Bangabandhu Sheikh Mujib Medical University, among 100 cases. Dissertation, BCPS, Dhaka; 2004.

7. Khastigir G studd J. Oestrogen and Osteoporosis. In studd .J. ed, progress in Obstetrics \& gynecology: Vol. 14. Edinburgh: Churchill Livingstone. 2002.

8. Woodman N. Read MD. Oophorectomy at hysterectomy. In studd. $\mathrm{J}$.ed. progress in obstestrics and Gynecology Vol- 14 Edinburgh: Churchill livingstone. 2000.

9. Jacobs 1. Hudson CN. Jacobs I. Shepherd JH. Oram D. eds. $2^{\text {nd }}$.Edition, ovarian cancer. Oxford: Oxford University; 2001.

10. Magos AL. Boornas N sinha R, Lo, L Richardson RE. Transvaginal endoscopic oophorectomy. Am. J. Obstet Gyneco.11995; 172: 123.

11. Howkins 1.lHudsion eN. Instrument: Operating theatre equipement basic surgical skills. In Shaw's Text Book of operative Gynaecology $6^{\text {th }}$ edition Churchill Livingstone. 2001; 63.

12. Dutta, De. Displacement of the uterus. In text book of Gynecology including contraceptiion. B'" edition. Konar H. calcatta. 2001;205.

13. Shergill SK. Shergill HK, Gupta M, Kaur. S. Clinicopathological study of hysterectomies. J Indian Med. Assoc. 2002(April); 100 (4): 2389,246.

14. Edouard. L. Rawson NS - Reliability of the recording of hysterectomy in Saskatchewan health care system. Br. J. obstet Gynaeco11996; 103: 891-7.

15. Nahar L. Clinical study of abdominal hysterectomy in Sir Salimullah Medical College \& Mitford Hospital, Dhaka. Among 100 cases. (Dissertation ) BCPS, Dhaka; 1999.

16. Dewan F. Clinical study of 100 cases of abdominal hysterectomy (Dissertation), BCPS, Dhaka, 1989.

17. Hassan Amirikia MD and LN. Evans. Ten year review of hysterectomies: Trends, indications and risks. AmJ. obstet Gynecol. 1979; 134: 43137.

18. Dicker RC, Scally MJ. Greenspan JR. Hysterectomy among woman of reproductive age: trends in the United States. 1982; 19701978. JAMA 248: 323-7.

19. Clarke A, Black N. Rowe P. Mott S, Howle K. Indications for and outcome of total abdominal hysterectomy for benign disease: a prospective cohort study.Br J Obstet Gynaecol. 1995; 102: 611-20.

20. Sculpher MJ. Dwyer N. Byford S, Stirrat GIM Randomised trial comparing hysterectomy and transcervical endometrial resection: effect on health related quality of life and costs 2 years after surgery. Br. J. obstet Gynecol. 1996; 142-9. 